\title{
Effect of ultrasonication on sensory and chemical stability of passion fruit juice during refrigerated storage
}

\author{
Vicente M. Gómez-López ${ }^{\text {* }}$, María E. Buitrago², María S. Tapia², Amaury Martínez-Yépez² \\ ${ }^{1}$ Cátedra Alimentos para la Salud, Universidad Católica de Murcia (UCAM), Campus de los Jerónimos 135, Guadalupe 30107, Murcia, Spain, \\ 2Instituto de Ciencia y Tecnología de Alimentos, Facultad de Ciencias, Universidad Central de Venezuela. Apartado 47097, Caracas 1041A, \\ Venezuela
}

\section{A B S T R A C T}

\begin{abstract}
Passion fruit juice (PFJ) is very susceptible to thermal degradation and may benefit from processing by non-thermal methods such as sonication. This study pursued to test the effect of sonication on sensory quality and related chemical compounds of PFJ during refrigerated storage. Treatment conditions were those of a previous study where a microbiologically stable PFJ was achieved. The effect of ultrasound $(20 \mathrm{kHz}, 263 \mathrm{~W}, 89.25 \mu \mathrm{m})$ on sensory quality, ${ }^{\circ} \mathrm{Brix}$, total titratable acidity (TTA), ${ }^{\circ}$ Brix/TTA and reducing and total sugars of PFJ during storage at $4{ }^{\circ} \mathrm{C}$ up to 10 days was studied. Sonication did not cause significant $(P>0.05)$ effects on TTA, ${ }^{\circ}$ Brix/TTA and reducing sugars but significantly $(\mathrm{P}<0.05)$ increased ${ }^{\circ} \mathrm{Brix}$ and total sugars content. Panel scored sonication PFJ significantly $(\mathrm{P}<0.05)$ lower in colour, flavour and aroma scores; but the global acceptance was similar $(P>0.05)$ than that of non-sonicated juice. Results indicate that sonication of PFJ is a treatment that does not affect the global sensory quality of the product.
\end{abstract}

Keywords: Aroma scores; Passion fruit; Storage; Ultrasonication

\section{INTRODUCTION}

Ultrasound treatment of fruit juices is part of the socalled non-thermal technologies, which have been in development in the last decades as an answer to the demand of consumers for fresh-like foods. High power ultrasound refers to pressure waves with a frequency of $20 \mathrm{KHz}$ or more that has the ability to cause cavitation bubbles. The collapse of bubbles generates an area of localized high temperature and pressure that brings about microbial inactivation (Piyasena et al., 2003). Sonication has been investigated as a way to provide high quality fruit juices. Besides its microbicidal effect, it can have deleterious effects on some quality parameters, however these are generally subtle (Tiwari et al., 2008a). The use of sonication in fruit juice processing is a topic of current interest; recent research has been conducted on juices from the following fruits among others: soursop (Dias et al., 2015), apple (Abid et al., 2014; Bastianello, et al., 2016), orange (Guerrouj et al., 2016) and cactus pear (Cruz-Cansino et al., 2016).
The demand of tropical or "exotic fruits has increased all over the world (Fresfel, 2015). Passion fruit is an exotic fruit which juice has a delicate aroma and flavour very sensitive to thermal treatment. Pasteurization of PFJ at $75{ }^{\circ} \mathrm{C} / 60$ $\mathrm{s}$ damages colour characteristics, sweet, characteristic and floral aroma and typical flavour (Sandi, Paes, Maia, Gomes \& Coelho, 2003), which includes a drastic reduction of the concentration of its four key volatiles (Sandi et al., 2004). Kuo, Chen, Wu \& Chen (2005) has reported 35\% loss of volatile components after treatment one-minute pasteurization at $85^{\circ} \mathrm{C}$. Therefore, a non-thermal treatment such as sonication might be suitable for producing highquality stable PFJ.

We have recently reported that ultrasound is able to bring about a microbiologically stable PFJ during storage at 4 ${ }^{\circ} \mathrm{C}$ with subtle effects on instrumental colour and ascorbic acid content (Gómez-López et al., 2017). However, the stabilization of fruit juices from the microbiological point of view lacks of practical significance if that is not

\footnotetext{
*Corresponding author:

Vicente M. Gómez-López, Universidad Católica de Murcia (UCAM), Campus de los Jerónimos 135, Guadalupe 30107, Murcia, Spain.

E-mail: vmgomez@ucam.edu
}

Received: 26 July 2017

Accepted: 07 January 2018 
accompanied by mild, null or even positive effects on their sensory stability. Therefore, this study was pursued to assess the effect of sonication, performed under conditions that have been proved to render a microbiologically stable product, on the sensory quality of passion fruit juice and some chemical constituents that can affect sensory attributes, namely: acidity, soluble solids and total and reducing sugars.

\section{MATERIALS AND METHODS}

\section{Preparation of passion fruit juice samples}

Yellow passion fruits (Passiflora edulisf. flavicarpa Degener) were purchased in a local market from Caracas, Venezuela. Fruits free of external defects were selected and washed. The juice was extracted using a commercial juice extractor (Omega Products, Inc., Harrisburg, PA). The fresh juice was standardized to a total soluble solids/total titratable acidity ratio of 5 using commercial sucrose and added with $425 \mathrm{mg}$ of calcium (Gynopharm, Venezuela) per $100 \mathrm{ml}$ of juice.

\section{Ultrasound treatment}

Ultrasonic treatment was carried out according to the standardized protocol of our laboratory, which has been described before (Gómez-López et al., 2010, 2017). In brief, ultrasound was applied to $100 \mathrm{ml}$ of PFJ placed in a $150 \mathrm{ml}$-double wall cylindrical vessel connected to a recirculation refrigerated water bath (Model 1268-24, Cole-Parmer, Chicago, IL). Juice temperature was set at $10{ }^{\circ} \mathrm{C}$ and was monitored with a thermopar. Ultrasound at a frequency of $20 \mathrm{kHz}, 89.25 \mu \mathrm{m}$ and $75 \%$ power was applied for 8 min using a Cole-Parmer CPX-500 ultrasonic unit working (Cole-Parmer, Chicago, IL) with a $13 \mathrm{~mm}$ diameter probe which tip was kept at $4 \mathrm{~cm}$ from the vessel bottom. Supposing a mean transducer efficiency of $70 \%$, the acoustic power actually supplied into the juice was 263 W according to Bevilacqua et al. (2014) equation. Treatment conditions were selected according to conclusions derived from Gómez-López et al. (2017).

\section{Stability of the sonicated juice}

Untreated (control) and sonicated PFJ were aseptically packed in sterile screwed-caps glass bottles and stored at $4{ }^{\circ} \mathrm{C}$ during 10 days. Samples were taken at time intervals and different quality indicators were evaluated. Sensory quality was evaluated by 30 judges, using a 1-9 hedonic scale for scoring colour, aroma, flavour and overall acceptance (9 like very much, 1 dislike very much, and 5 as rejection point). Total soluble solids were determined with a manual refractometer (Atago PR-101, Tokyo, Japan) and expressed in Brix degrees corrected to $25^{\circ} \mathrm{C}$ (method 932.12, AOAC, 1990). Total titratable acidity was measured by titration with $\mathrm{NaOH}$ (method 942.15 B, AOAC, 1990) expressed as citric acid percent. Total and reducing sugars were determined by Lane and Eynon titration using Fehling's solution as described by AOAC (1990) method 925.35. All measurements were made in triplicate.

\section{Data analysis}

Data was checked for homoscedasticity using the Levene's test. Since data is not normally distributed, it was analysed with the Wilcoxon Signed-Ranks test in order to compare trends between control and sonicated samples during storage. Additionally, Kruskal-Wallis and Mann-Withney test were carried out to detect statistical differences between control and treated samples and also to detect differences during storage time within groups. All analysis used $\mathrm{P}<0.05$ and were performed using the software IBM SPSS Satatistics 24.

\section{RESULTS AND DISCUSSION}

\section{Chemical parameters}

The focus of this research was the stability of sonicated PFJ during refrigerated storage from the sensory point of view. Treatment conditions were selected based in a previous study where their antimicrobial efficacy had been proved (Gómez-López et al., 2017). Total solid soluble content measured in ${ }^{\circ}$ Brix, total titratable acidity (TTA), their ratio $\left({ }^{\circ} \mathrm{Brix} / \mathrm{TTA}\right)$, and reducing and total sugars are some of the factors that affect the sensory quality of this juice. The analysis of trends by the Wilcoxon Signed-Ranks test shows that sonication produced a significant $(\mathrm{P}<0.05)$ increase in ${ }^{\circ}$ Brix, while it did not affect TTA and ${ }^{\circ}$ Brix/ TTA (Table 1). Also, it caused a significant $(\mathrm{P}<0.05)$ higher concentration of total sugars but not of reducing sugars (Table 2). A day-by-day analysis by the Mann-Withney test shows that immediately after treatment, sonication produced a significant $(\mathrm{P}<0.05)$ increase in ${ }^{\circ} \mathrm{Brix}$, while it did not affect TTA and ${ }^{\circ}$ Brix/TTA (Table 1). Also, it caused a significant $(\mathrm{P}<0.05)$ increase in total sugars but not in reducing sugars (Table 2 ).

Carbohydrates constitute the major component of ${ }^{\circ} \mathrm{Brix}$ of passion fruit, and are mainly composed by similar proportions of three sugars, the reducing sugars glucose and fructose, and the non-reducing sugar sucrose (Pruthi, 1963). Since more sucrose was added during juice standardization, it became the carbohydrate present in the highest concentration. Therefore, the increase in ${ }^{\circ} \mathrm{Brix}$ (Table 1) is consistent with the increase of total sugars, likely mainly due to a higher detection of sucrose given the absence of effect on reducing sugars (Table 2). The increase of both, ${ }^{\circ}$ Brix and total sugars, due to sonication has also been observed in carrot juice (Zou and Jiang, 2016), and the 
Gómez-López, et al.

Table 1: Total solid soluble content (Brix) and total titratable acidity (TTA) (g citric acid/100 ml juice) of untreated and sonicated passion fruit juice during storage at $4 \stackrel{\circ}{\circ}$

\begin{tabular}{|c|c|c|c|c|c|c|}
\hline \multirow[t]{2}{*}{ Time (days) } & \multicolumn{2}{|c|}{ oBrix } & \multicolumn{2}{|c|}{ TTA } & \multicolumn{2}{|c|}{ oBrix/TTA } \\
\hline & Control & Sonicated & Control & Sonicated & Control & Sonicated \\
\hline 0 & $17.27 \pm 0.06^{\text {by }}$ & $17.53 \pm 0.06^{\mathrm{bz}}$ & $3.52 \pm 0.08^{\mathrm{ab}}$ & $3.52 \pm 0.05^{\mathrm{ab}}$ & $4.91 \pm 0.09^{b c}$ & $4.98 \pm 0.09^{c d}$ \\
\hline 2 & $17.30 \pm 0.00^{\mathrm{b}}$ & $17.57 \pm 0.38^{b}$ & $3.36 \pm 0.12^{\text {ay }}$ & $3.84 \pm 0.00^{\mathrm{cdz}}$ & $5.15 \pm 0.19^{c z}$ & $4.57 \pm 0.10^{\text {aby }}$ \\
\hline 4 & $17.17 \pm 0.15^{\text {by }}$ & $17.53 \pm 0.06^{\mathrm{bz}}$ & $3.59 \pm 0.08^{\mathrm{ab}}$ & $3.66 \pm 0.01^{b c}$ & $4.78 \pm 0.14 a^{b c}$ & $4.79 \pm 0.03^{\mathrm{bcc}}$ \\
\hline 6 & $16.73 \pm 0.12^{\mathrm{a}}$ & $16.90 \pm 0.10^{a}$ & $3.76 \pm 0.04^{\mathrm{bz}}$ & $3.34 \pm 0.17^{\text {ay }}$ & $4.45 \pm 0.07^{\text {ay }}$ & $5.07 \pm 0.27^{\mathrm{dz}}$ \\
\hline 8 & $17.13 \pm 0.06^{\text {by }}$ & $17.47 \pm 0.12^{\mathrm{bz}}$ & $3.78 \pm 0.23^{b}$ & $3.99 \pm 0.02^{d}$ & $4.54 \pm 0.27^{a b}$ & $4.38 \pm 0.02^{a}$ \\
\hline 10 & $16.77 \pm 0.12^{\mathrm{a}}$ & $17.00 \pm 0.00^{\mathrm{ab}}$ & $3.68 \pm 0.01^{b}$ & $3.62 \pm 0.07^{b}$ & $4.55 \pm 0.04^{\mathrm{ab}}$ & $4.70 \pm 0.09^{\mathrm{abc}}$ \\
\hline
\end{tabular}

$\mathrm{a}, \mathrm{b}, \mathrm{c}$ : Means within a column lacking a common superscript letter are significantly different $(\mathrm{P}<0.05)$. y, $\mathrm{z}$ : Means within a parameter and row lacking a common superscript letter are significantly different $(\mathrm{P}<0.05)$. In yellow: Analysed by non-parametric tests for control-treated differences.

Table 2: Reducing and total sugars of untreated and sonicated passion fruit juice during storage at $4 \stackrel{\circ}{\circ} \mathrm{C}$

\begin{tabular}{lccccc}
\hline $\begin{array}{l}\text { Time } \\
\text { (days) }\end{array}$ & \multicolumn{2}{c}{ Reducing sugars } & & \multicolumn{2}{c}{ Total sugars } \\
\cline { 2 - 3 } \cline { 5 - 6 } & Control & Sonicated & & Control & Sonicated \\
\hline 0 & $2.52 \pm 0.10^{\mathrm{bc}}$ & $2.42 \pm 0.33^{\mathrm{a}}$ & & $5.46 \pm 0.65^{\mathrm{aby}}$ & $6.57 \pm 0.46^{\mathrm{az}}$ \\
2 & $1.93 \pm 0.05^{\mathrm{ay}}$ & $2.60 \pm 0.13^{\mathrm{abz}}$ & & $6.18 \pm 0.31^{\mathrm{b}}$ & $6.96 \pm 0.96^{\mathrm{a}}$ \\
4 & $2.28 \pm 0.15^{\mathrm{b}}$ & $2.41 \pm 0.05^{\mathrm{a}}$ & & $4.77 \pm 0.42^{\mathrm{ay}}$ & $5.83 \pm 0.12^{\mathrm{az}}$ \\
6 & $3.20 \pm 0.15^{\mathrm{dz}}$ & $2.71 \pm 0.04^{\text {aby }}$ & & $5.87 \pm 0.31^{\mathrm{ab}}$ & $6.38 \pm 0.58^{\mathrm{a}}$ \\
8 & $2.88 \pm 0.04^{\mathrm{cdz}}$ & $2.70 \pm 0.03^{\mathrm{aby}}$ & & $6.30 \pm 0.42^{\mathrm{b}}$ & $5.85 \pm 0.31^{\mathrm{a}}$ \\
10 & $2.89 \pm 0.28^{\mathrm{cd}}$ & $3.10 \pm 0.15^{\mathrm{b}}$ & & $5.68 \pm 0.16^{\mathrm{ab}}$ & $6.20 \pm 0.34^{\mathrm{a}}$ \\
\hline
\end{tabular}

a, b, c: Means within a column lacking a common superscript letter are significantly different $(P<0.05)$. $y, z$ : Means within a parameter and row lacking a common superscript letter are significantly different $(P<0.05)$.

increase of ${ }^{\circ}$ Brix in green cactus pear juice (Cruz-Cansino et al., 2016), although no effect of sonication on ${ }^{\circ}$ Brix and TTA has been reported in other cases (Tiwari et al., 2008b, 2009; Adekunte et al., 2010). Similarly, sonication increased the contents of sugars in melon juice (Fonteles et al., 2012), carrot juice (Jabbar et al., 2014) and apple juice (Abid et al., 2014). This kind of result have been attributed to a higher extraction efficiency caused by ultrasound treatment due to cell disruption and to a mechanical effect that increases solid-liquid contact surface, which allows sugars trapped in the interior of juice particles to permeate to the juice liquid phase (Abid et al., 2014; Jabbar et al., 2014; Cruz-Cansino et al., 2016; Zou and Jiang, 2016). Once there, it is more detectable. The effects of sonication on the extractability of compounds have been widely documented, and that is indeed one of its applications (Rastogi, 2011). Therefore, the increase of ${ }^{\circ}$ Brix and total sugars seems to be apparent, i.e., more related to an easier detection of compounds already present in the original juice rather than actual chemical changes.

Changes of physic-chemical parameters during storage followed the same trends for both, control and sonicated samples, as shown by analysis using Kruskal-Wallis and Mann-Withney tests. There were significant $(\mathrm{P}<0.05)$ reductions in ${ }^{\circ}$ Brix and ${ }^{\circ} \mathrm{Brix} / \mathrm{T}$ TA values (Table 1 ), and significant increase $(\mathrm{P}<0.05)$ in TTA (Table 1) and reducing sugars (Table 2 ), while there were no statistical differences $(\mathrm{P}>0.05)$ for total sugars between day 0 and 10 although some significant differences $(\mathrm{P}<0.05)$ are noticed at intermediate values for the control juice. These results taken together indicate that, in spite of some differences at certain days, the physic-chemical parameters analysed followed the same trends during storage, which supports the conclusion that sonication has not a meaningful impact on the stability of passion fruit juice.

\section{Sensory quality}

Sonication significantly $(\mathrm{P}<0.05)$ decreased panel scores for colour, flavour and aroma although differences were small, and it did not affect $(\mathrm{P}>0.05)$ global acceptance (Fig. 1), when trends were analysed by the Wilcoxon Signed-Ranks test. The detailed analysis by using the Mann-Withney test shows that immediately after treatment (day 0) sonication significantly $(\mathrm{P}<0.05)$ decreased judges scores for aroma and increased $(\mathrm{P}<0.05)$ their flavour scores without affecting colour $(\mathrm{P}>0.05)$ evaluation; although differences did not affect $(\mathrm{P}>0.05)$ global acceptance (Fig. 1). Control and sonicated juices got their sensory quality deteriorated during storage in a very similar way. In general, the sensory quality was very stable up to day 8 and decreased at the $10^{\text {th }}$ day in both kind of samples. Colour was the parameter less affected by sonication since sonicated samples were scored significantly lower $(\mathrm{P}<0.05)$ than control samples only the $4^{\text {th }}$ day of storage. On the contrary, flavour and aroma scores were considered slightly poorer by the panel in sonicated samples during storage except for the final day $(\mathrm{P}<0.05)$. However, judges did not give much relevance at the time of assessing the overall quality of the juices, which was rated very similarly during most of the storage time and especially at the end of it (Fig. 1D). It is also noteworthy that all evaluated attributes kept scores higher than the rejection point during the storage time at $4{ }^{\circ} \mathrm{C}$. In general, lower scores for sonicated samples were given immediately after treatment and persisted during storage. Immediate differences were also observed for sonicated orange juice (Gómez-López et al., 2010), but they disappeared during storage due to a faster deterioration of control samples.

The results of colour evaluation are in line with those of a study carried out under identical conditions (Gómez-López et al., 2017), where sonication affected PFJ colour measured 


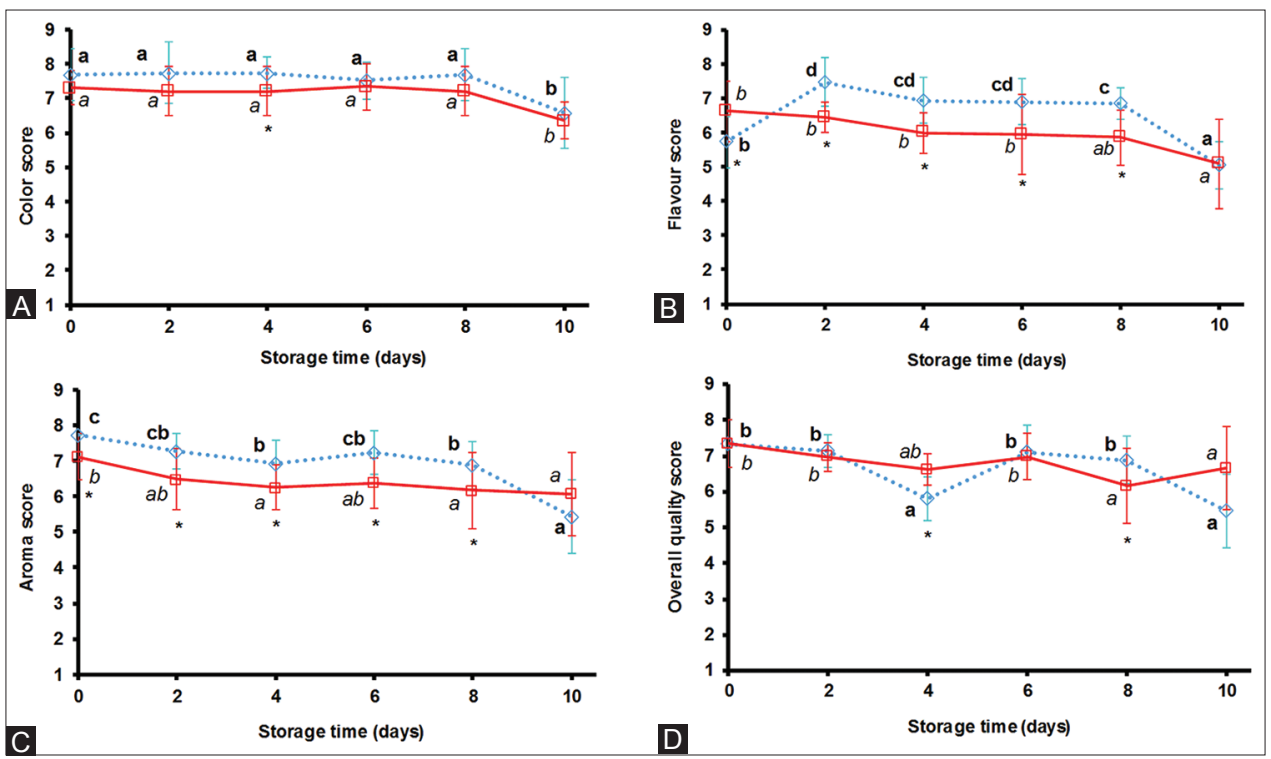

Fig 1. Colour (A), flavour (B), aroma (C), and overall quality (D) of passion fruit juice stored at $4 \stackrel{\circ}{\circ}$. Scores: $1=$ dislike extremely, $3=$ dislike moderately, $5=$ neither like or dislike, $7=$ like moderately, and $9=$ like extremely. $a, b, c, d$ : means within the line representing data for untreated juice $(\cdots \triangleright \cdots)$ lacking a common letter are significantly different. a,b,c,d: means within the line representing data for sonicated juice (_——) lacking a common letter are significantly different. Asterisks indicate statistical differences between untreated and sonicated samples for the specific storage time. All statistical differences are with $\mathrm{P}<0.05$.

instrumentally, causing that the juice became lighter, greener and yellower. In spite of the observed effects, these were not considered relevant by the judges when assessing the overall quality of control and sonicated juice.

There are scarce reports on the effects of sonication on sensory quality of fruit juices during storage, although some studies have measured its effect on instrumental colour parameters. Sonication had no effect on appearance, aroma and taste of soursop juice; even though differences were detected in instrumental colour parameters, they were not seen by naked eyes (Dias et al., 2015). Changes in colour parameters have been observed to occur after sonication of orange (Adekunte et al., 2010) and tomato juice (Tiwari et al., 2008b), the latter including an increase in lightness. Sonication consequences on fruit juice colour have been attributed to cavitation effects, which can accelerate chemical reactions, increase diffusion rates, disperse aggregates and breakdown susceptible particles (Sala et al., 1995). Sonication can also cause the isomerization of carotenoids (Chen et al., 1995), which are the major pigments in yellow PFJ (Fernandes et al., 2011).

Other related studies have established the aroma as a key factor in the sensory stability of sonicated fruit juices and have related its deterioration with the increase in microbial populations during storage (Gómez-López et al., 2010; Guerrouj et al., 2016). For example, increased levels of unpleasant carboxylic acids that are strictly linked to yeast metabolism have been detected in fresh apple juice but not in sonicated samples (Bastianello et al., 2016). It has been reported (Gómez-López et al., 2017) that under the applied sonication conditions, PFJ microbial populations do not exceed $6.5 \log \mathrm{CFU} / \mathrm{ml}$, limit that has been related to sensory deterioration in sonicated juices (Gómez-López et al., 2010).

\section{CONCLUSION}

The sensory stability of sonicated passion fruit juice stored at $4{ }^{\circ} \mathrm{C}$ was assessed together with relevant chemical parameters. Sonication did not cause significant $(\mathrm{P}>0.05)$ effects on total titratable acidity, ${ }^{\circ} \mathrm{Brix} /$ total titratable acidity and in reducing sugars but significantly $(\mathrm{P}<0.05)$ increased ${ }^{\circ}$ Brix and total sugars content. Panel scored sonication passion fruit juice significantly $(\mathrm{P}<0.05)$ lower in colour, flavour and aroma scores; but the global acceptance was similar than that of control juice. Results show that sonication of passion fruit juice is a treatment mild enough to not affect sensory quality when carried out under conditions that have been proved earlier that can prolong the microbiological stability of this product.

\section{ACKNOWLEDGMENT}

This research was supported by FONACIT project G-2000001538.

\section{Author contributions}

V.M.G.L.: He designed experiments, analyzed results and prepared the manuscript. M.E.B.: performed all experiments. M.S.T. and A.M.Y.: they helped in designing and supervised experiments. 


\section{REFERENCES}

Abid, M., S. Jabbar, T. Wu, M. M. Hashim, B. Hu, S. Lei and X. Zeng. 2014. Sonication enhances polyphenolic compounds, sugars, carotenoids and mineral elements of apple juice. Ultrason. Sonochem. 21: 93-97.

Adekunte, A.O., B. K. Tiwari, P. J. Cullen, A. G. M. Scannell and C. P. O'Donell. 2010. Effect of sonication on colour, ascorbic acid and yeast inactivation in tomato juice. Food Chem. 122: 500-507.

AOAC. 1990. Official Methods of Analysis of the Association of Official Analytical Chemists. AOAC, Virginia, USA.

Bastianello, E., F. Montemurro, L. Fasolato, S. Balzan, G. Marchesini, B. Contiero, B. Cardazzo and E. Novelli. 2016. Volatile compounds and microbial development in sonicated cloudy apple juices: Preliminary results. CyTA J. Food. 14: 65-73.

Bevilacqua, A., B. Speranza, D. Campaniello, M. Sinigaglia and M. R. Corbo. 2014. Inactivation of spoiling yeasts of fruit juices by pulsed ultrasound. Food Bioprocess Technol. 7: 2189-2197.

Chen, H. E., H. Y. Peng and B. H. Chen. 1995. Changes of carotenoids, colour and vitamin A contents during processing of carrot juice. J. Agric. Food Chem. 43: 1912-1918.

Cruz-Cansino, N. S., I. Reyes-Hernández, L. Delgado-Olivares, D. P. Jaramillo-Bustos, J. A. Ariza-Ortega and E. RamírezMoreno. 2016. Effect of ultrasound on survival and growth of Escherichia coli in cactus pear juice during storage. Braz. J. Microbiol. 47: 431-437.

Dias, D. R. C., Z. M. P. Barros, C. B. O. Carvalho, F. A. Honorato, N. B. Guerra and P. M. Azoubel. 2015. Effect of sonication on sour soup juice quality. LWT Food Sci. Technol. 62: 883-889.

Fernandes, A. G., G. M. Santos, D. S. Silva, P. H. M. Sousa, G. A. Maia and R. W. Figueiredo. 2011. Chemical and physicochemical characteristics changes during passion fruit juice processing. Cienc. Tecnol. Aliment (Campinas). 31: 747-751.

Fresfel, European Fresh Produce Association. (2015). Position Paper: Exotic Fruit - A Highlight at POS. Consumption and Trends. Fruit Logistica, Berlin February 5, 2015. Available from: http://www. freshfel.org/docs/2015/Position_Papers/FRESHFEL_-_Exotic_ fruit_5.02.2015.pdf. [Last accessed on 2017 Jul 18].

Fonteles, T. V., M. G. M. Costa, A. L. T. de Jesus, M. R. A. Miranda, F. A. N. Fernandes and S. Rodrigues. 2012. Power ultrasound processing of cantaloupe melon juice: Effects on quality parameters. Food Res. Int. 48: 41-48.

Gómez-López, V. M., L. Orsolani, A. Martínez-Yépez and M. S. Tapia. 2010. Microbiological and sensory quality of sonicated calciumadded orange juice. LWT Food Sci. Technol. 43: 808-813.

Gómez-López, V. M., M. E. Buitrago, M. S. Tapia and A. MartínezYépez. 2017. Effect of ultrasonication on microbial quality, color and ascorbic acid of passion-fruit juice during storage. Acta Aliment., 46(4): 470-480. (In Press).

Guerrouj, K., M. Sánchez-Rubio, A. Taboada-Rodríguez, R. M. CavaRoda and F. Marín-Iniesta. 2016. Sonication at mild temperatures enhances bioactive compounds and microbiological quality of orange juice. Food Bioprod. Process. 99: 20-28.

Jabbar, S., M. Abid, B. Hu, T. Wu, M. M. Hashim, S. Lei, X. Zhu and X. Zeng. 2014. Quality of carrot juice as influenced by blanching and sonication treatments. LWT Food Sci. Technol. 55: 16-21.

Kuo, M. C., S. L., Chen, C. M. Wu and C. C. Chen. 2005. Changes in volatile components of passion fruit juice as affected by centrifugation and pasteurization. J. Food Sci. 50: 1208-1210.

Piyasena, P., E. Mohareb and R. C. McKellar. 2003. Inactivation of microbes using ultrasound: A review. Int. J. Food Microbiol. 87: 207-216.

Pruthi, J. S. 1963. Physiology, chemistry, and technology of passion fruit. Adv. Food Res. 12: 203-282.

Rastogi, N. K. 2011. Opportunities and challenges in application of ultrasound in food processing. Crit. Rev. Food Sci. Nut. 51: 405-722.

Sala, F. J., J. Burgos, S. Condon, P. Lopez and J. Raso. 1995. Effect of heat and ultrasound on microorganisms and enzymes. In: G. W. Gould (Ed.), New Methods of Food Preservation, Blackie Academic \& Professional, London, UK, pp. 176-204.

Sandi, D., J. B. P. Chaves, J. F. M. Parreiras, A. C. G. De Souza and M. T. C. Da Silva. 2003. Avaliação da qualidade sensorial de suco de maracujá amarelo (Passiflora edulis var. flavicarpa) submetido à pasteurização e armazenamento. Boll. CPPA. 21: 141-158.

Sandi, D., J. B. P. Chaves, A. C. G. De Souza, J. F. M. Parreiras, M. T. C. Da Silva and P. B. L. Constant. 2004. Hunter color dimensions, sugar content and volatile compounds in pasteurized yellow passion fruit juice (Passiflora edulis var. flavicarpa) during storage, Braz. Archiv. Biol. Technol. 47: 233-245.

Tiwari, B. K., P. O. O'Donnell, K. Muthukumarappan and P. J. Cullen. 2008a. Effect of ultrasound processing on the quality and nutritional properties of fruit juices. Stewart Postharvest Rev., 5: $1-6$.

Tiwari, B. K., K. Muthukumarappan, P. O. O’Donnell and P. J. Cullen. 2008b. Effect of sonication on the kinetics of orange juice quality parameters. J. Agric. Food Chem. 56: 2423-2428.

Tiwari, B. K., P. O. O'Donnell, K. Muthukumarappan and P. J. Cullen. 2009. Effect of sonication on orange juice quality parameters during storage. Int. J. Food Sci. Technol. 44: 586-595.

Zou, Y. and A. Jiang. 2016. Effect of ultrasound on quality and microbial load of carrot juice. Food Sci. Technol (Campinas). 36: 111-115. 